\title{
Edificios escolares: ¿Infraestructura inclusiva?
}

\author{
Edelmira Arellanes Corral \\ Escuela Normal Superior "Profr. José E. Medrano R." \\ edelmiraarellanes@yahoo.com.mx
}

\begin{abstract}
Resumen
Los edificios escolares en México no cuentan, en su mayoría, con las medidas de seguridad para todas las personas, ya que no todos los usuarios pueden desplazarse por ellos de forma libre y sin dificultad independientemente de su condición física; es necesario son necesarias adecuaciones para que las personas con movilidad reducida puedan circular sin dificultad; también se requiere que en la construcción de los nuevos edificios escolares se considere el hecho de que existen personas con algún tipo de diversidad funcional. Se realizó un diagnóstico a la infraestructura escolar de las secundarias públicas en la Cd. de Chihuahua mediante la observación directa con la utilización de instrumentos como: una lista de cotejo, diario de campo y fotografía. La investigación abarca otro tipo de barreras ajenas a las físicas, como las sociales y culturales. Éstas se rescataron a través de entrevistas con los actores escolares con este tipo de movilidad (profesorado y alumnado). Se encontró que, la escuela, al igual que la infraestructura urbana social, presenta barreras que discriminan a quienes padecen discapacidad; basta observar el diseño de sus edificios, que fueron construidos considerando que la mayoría de las personas pueden acceder fácilmente, sin embargo existe quienes, por algún problema físico, transitorio o permanente, no consiguen hacerlo o lo hacen con dificultad. La escuela, debiera de ser el ejemplo social que provea de un entorno en el que se ensayen nuevas formas de relación; la infraestructura escolar, expresa lo contrario.
\end{abstract}

\section{Palabras clave}

Accesibilidad, inclusión, discriminación, infraestructura, barreras arquitectónicas.

\section{Antecedentes}

En el entorno físico actual, quienes padecen movilidad reducida temporal o permanente, se enfrentan a la frustración de no poder acceder con facilidad a todos los lugares que se desee ya que el estacionamiento para discapacitados regularmente se encuentra lejos de la entrada, o simplemente las banquetas no están diseñadas para uso universal, salvo algunos sectores como por ejemplo el centro de nuestra ciudad.

La escuela no es la excepción; el diseño de sus edificios, se hizo considerando únicamente que la mayoría de las personas pueden acceder fácilmente, sin embargo existe quienes, a consecuencia de algún problema físico, transitorio o permanente, no les es posible hacerlo o lo hacen con dificultad.

En el Foro Mundial sobre la Educación abril del 2000, se estableció el compromiso de alcanzar un entorno educativo seguro, sano, integrado y dotado de recursos distribuidos de modo equitativo.

La educación, a lo largo de toda la vida, descansa en cuatro principios básicos: aprender a conocer, aprender a hacer, aprender a ser y aprender a vivir juntos, refiriéndose este último a las aptitudes para vivir una vida libre de discriminaciones en la que todas las personas tienen iguales oportunidades para lograr su desarrollo individual, y el de sus familias y comunidades. 
Este concepto de educación proporciona una visión integrada del significado de aprendizaje y la calidad de la educación. (Delors y otros, 1996).

La reflexión es imperativa, pues no puede ser posible que en pleno siglo XXI haya a quien se le niegue el acceso a la educación por el hecho de poseer una discapacidad, esto conlleva a la discriminación por discapacidad física.

Estas construcciones son el resultado de conductas discriminatorias por parte de la sociedad en general, las cuales pasan desapercibidas o se vuelven parte de la cotidianidad y se convierte en un suceso invisible que parece no sorprender a nadie, salvo a quien adolece de la dificultad.

\section{La Discapacidad y la Educación en Cifras}

Según la Organización Mundial de la Salud (OMS), el $10 \%$ de la población mundial presenta algún grado discapacidad. En México el $2.3 \%$ de su población tiene algún tipo de discapacidad. $(1.8 \%$ de la población total, según el censo del año 2000 INEGI).

El Instituto Nacional de Estadística, Geografía e Informática (INEGI), ha establecido una diferenciación entre los tipos de discapacidad, así como una distribución porcentual de la población, siendo los más conocidos: motriz $45.3 \%$, visual $26 \%$, mental $16.1 \%$, auditiva $15.7 \%$, de lenguaje $4.9 \%$. La suma de estos porcentajes es mayor a 100 dado que algunas personas pueden poseer más de un tipo de discapacidad.
Conforme al XII Censo General de Población y Vivienda 2000 del INEGI, del total de la población de entre 6 y 14 años, el 91\% asiste a la escuela, mientras que de quienes presentan alguna discapacidad, solamente el $63 \%$.

Según este mismo censo, de las personas de entre 15 y 29 años con alguna discapacidad, solamente el $15.5 \%$ asiste a la escuela. Ahora bien, de la población en general, el $10 \%$ no sabe leer ni escribir, en tanto en la población con discapacidad, la cifra se incrementa a $32.9 \%$.

De las personas mayores de 14 años con discapacidad, el $4 \%$ cuenta con educación superior, $5 \%$ han cursado algún grado de educación media superior; $7 \%$ tienen educación básica completa, mientras que un $46 \%$ tienen educación básica (primaria y secundaria) incompleta. Además el 36\% no cursa ningún grado escolar. (INEGI 2000, a).

\section{Antecedentes conceptuales}

La Clasificación Internacional de Deficiencias, Discapacidades y Minusvalías (CIDDM), desarrollado por la OMS, publicada en $1980 \mathrm{y}$ difundido en el año 2000, sirvió de marco para el levantamiento del XII Censo General de Población y Vivienda 2000. Aquí se plantea la incorporación de tres niveles diferentes, que se interrelacionan de forma más compleja. En la práctica, no puede establecerse una línea divisoria clara entre cada elemento; por ejemplo, puede haber una deficiencia sin que de lugar a enfermedades o discapacidades e incluso deficiencias" (INEGI, 2004, p. 23).

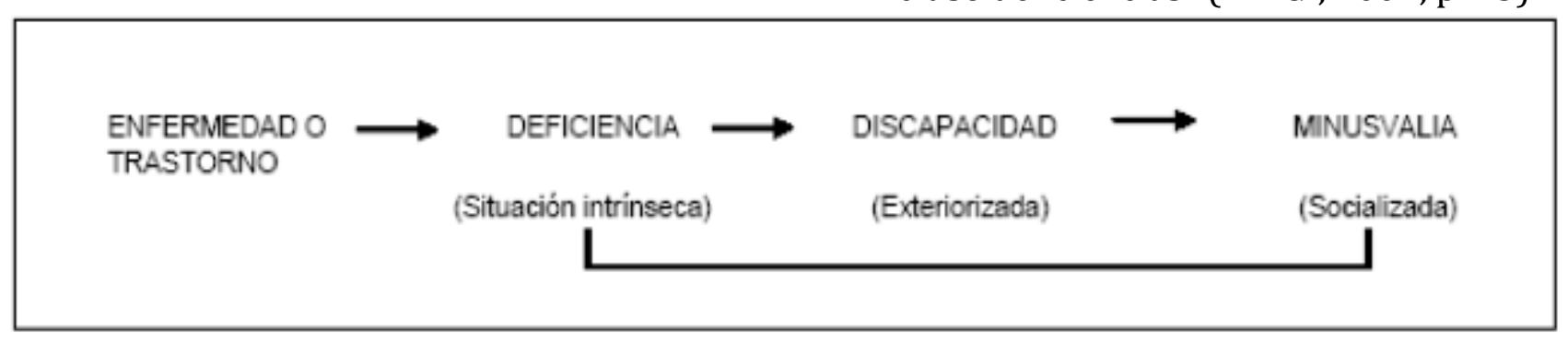


Una discapacidad es la disminución o pérdida de una temporal o permanente, para desarrollar una o más actividades de la vida diaria, dentro del margen considerado como normal, que puede ser causada o agravada por el entorno. Existen discapacidades diversas, sin embargo nuestro objeto de estudio es la discapacidad motriz, que está presente en todas las personas que tienen dificultad para moverse, caminar, mantener ciertas posturas o para desarrollar habilidades como sostener objetos.

Se considera a la accesibilidad como la permisividad del desplazamiento independiente y sin obstáculos a todas las personas. Constituye la posibilidad de que se pueda gozar de las condiciones de seguridad y autonomía como elemento primordial para el desarrollo de las actividades de la vida diaria, sin restricciones derivadas del ámbito físico o del transporte, para su integración y equiparación de oportunidades.

La movilidad reducida es el término que se aplica a aquellas personas que, por efecto y consecuencia de alguna discapacidad, transitoria o permanente, presentan dificultad para trasladarse o movilizarse de manera libre y rápida para la realización de sus actividades restringidas para la realización de sus actividades. Se ha edificado un mundo tomando como referente a las personas sanas y jóvenes, el ideal de persona que se ha construido rinde culto a la juventud, a la destreza intelectual, física y psicológica; la "normalidad" se acerca al perfeccionismo.

Se ha construido una cultura en la que toda aquella persona que no se amolde a esos ideales colectivos, se vuelve víctima de la segregación y el rechazo, probablemente inconscientes e involuntarios, pero expresados de varios modos como "los viejos", "los minusválidos", y que generalmente se encuentran fuera del proceso productivo.

Ésta es una práctica discriminatoria ya que al realizar las construcciones con características inaccesibles, se está coartando dicha igualdad de oportunidades, se está faltando a un principio general del derecho ligado íntimamente con la justicia: la equidad; entendida ésta como la disposición del ánimo que mueve a dar a cada uno lo que merece.

\section{Considerandos: Legislación vigente}

La Ley General de Educación obliga a las autoridades a tomar las medidas necesarias para que haya condiciones adecuadas para una mayor equidad educativa e igual oportunidad de acceso y permanencia en la escuela, pues como servicio público, debe ofrecer facilidades para personas con discapacidad. Los datos del INEGI permiten darse cuenta que se requieren edificios con condiciones arquitectónicas accesibles y las escuelas no lo son.

Nuestras leyes no definen claramente si pretenden la inclusión o la integración de las personas con discapacidad en las escuelas. Werneck (s/f) define inclusión como "inserción total e incondicional de niños con discapacidad que no necesitan "prepararse" para la escuela regular". Menciona también a la integración, que la señala como "inserción parcial y condicionada de los niños, que "se preparan" en escuelas o clases especiales para poder asistir a escuelas o aulas regulares".

Cuando hay inclusión, la sociedad se adapta para atender las necesidades de las personas con discapacidad y se vuelve más atenta a las necesidades de todas las personas. Se defiende el derecho de las personas con y sin discapacidad. Se valoriza la individualidad de quienes presentan discapacidad, a partir del hecho real de que todos los individuos somos diferentes; no existen "especiales", "normales", "excepcionales"; simplemente son personas con discapacidad. La inclusión exige rupturas en los sistemas y transformaciones profundas.

Cuando solamente se da la integración, las personas que presentan alguna discapacidad, deben adaptarse a las necesidades de los modelos que ya existen en 
la sociedad que solamente realiza ciertos ajustes, disfrazando las limitaciones para aumentar las posibilidades de inserción. La integración se contenta con llevar a cabo transformaciones superficiales del entorno.

La escuela inclusiva (Adirón, 2005) es aquella donde el modelo educativo altera la lógica de la no aceptación de la diversidad, resalta la perpetuidad de las diferencias insuperables, y pretende establecer vínculos entre alumnado y currículo para que aprendan a resolver problemas cotidianos, que los preparen para aprovechar oportunidades que la vida les ofrece, las cuales en ocasiones tendrán que ser construidas y en las que las personas con discapacidad tienen que participar activamente.

La educación segregadora tiende a perpetuar una forma de pensar que encadena a las personas a lo largo de sus vidas. Nuestro sistema de educación básica es fuertemente inequitativo y representa aún el filtro social más importante para la participación y la movilidad social.

El bajo nivel de participación de las personas con discapacidad, puede estar vinculada directamente a su exclusión en el sistema educativo. Puede afirmarse que la separación persistente de las personas con discapacidad por parte de la sociedad dominante debilita el tejido social y daña la diversidad. La supresión de las barreras arquitectónicas en la infraestructura educativa es un derecho de todas las personas, que debe ejercerse de manera inmediata.

\section{Acuerdos internacionales}

En el ámbito internacional, en varios países y organizaciones se trabaja a favor de que las personas con discapacidad tengan igualdad de oportunidades, sobre todo en el acceso a la educación. En la Declaración del Milenio de las Naciones Unidas hecha en el año 2000, se enuncia el compromiso de alcanzar la enseñanza primaria universal en el 2015
(EPT, 2005), es decir, que todas las personas accedan a la educación.

En las Conferencias Internacionales de las Naciones Unidas sobre la Educación, se reiteran estas declaraciones, reconociendo que la calidad de la educación es primordial para la consecución de la Educación para Todos; así, en la Declaración Mundial sobre Educación para todos de Jomtien (1990), en el artículo $3^{\circ}$ se declara: Universalizar el acceso a la educación y fomentar la equidad.

En el Foro Mundial sobre la Educación de Dakar, Senegal (2000), los países participantes se comprometen a crear un entorno educativo seguro, sano, integrado y dotado de recursos distribuidos equitativamente.

Para Schmelkes (1996), la calidad de la educación se constituye por cuatro componentes: relevancia, eficacia, eficiencia y equidad, cuya última acepción significa el reconocimiento de la diversidad en todos sus sentidos y su incidencia sobre las oportunidades de escolaridad y aprendizaje; es apoyar de manera diferencial a quien más lo necesite.

La reflexión es imperativa; no puede ser posible que en pleno siglo XXI haya personas a las que se les niegue el acceso a la educación, solo por poseer una discapacidad, esto significa discriminación por discapacidad física.

\section{Investigación sobre accesibilidad}

Durante el año 2009, se desarrolló un diagnóstico sobre las condiciones que guardan los edificios escolares de las secundarias públicas de la ciudad de Chihuahua, en la que algunos de los resultados parciales muestran que de 46 edificios solamente uno presenta condiciones de accesibilidad universal, excepto bebederos y tiendita escolar, el resto de los edificios solamente cuenta con adecuaciones parciales pero carecen de la universalidad del acceso. 
La investigación total se adscribe a un paradigma crítico en el que no se puede permanecer contemplativo ante una problemática, su misión es transformar. En este paradigma, producir conocimientos es producir valores.

Para poder saber qué cambiar, primero se diagnosticó. Es la parte de la investigación que se informa, pero es importante ofrecer una vista panorámica de todo lo realizado. Como método de investigación del diagnóstico se utilizó la encuesta, y entre las técnicas de recogida de información se utilizó el cuestionario, la observación a través de una lista de cotejo, la entrevista y el registro fotográfico. Se creó, utilizando la Norma Oficial Mexicana que establece los requisitos arquitectónicos para facilitar el acceso a los establecimientos del Sistema Nacional de Salud, una lista de cotejo para la realización del diagnóstico de las condiciones de accesibilidad de cada uno de los edificios escolares. Las entrevistas se dirigieron a personal directivo, docente en general y docentes con movilidad reducida, así como alumnado con movilidad reducida y padres y madres de este alumnado. Por último la observación se realizó en los espacios interiores y exteriores de las escuelas, así como en algunas sesiones de clase de grupos en los que existe alumnado con movilidad reducida y se registró a través del diario de la investigadora y de la toma de fotografías.

Esta investigación tiene como característica muy particular el uso de la fotografía como estrategia de registro de la evidencia empírica ya que lo encontrado es difícil detallarlo exclusivamente en forma verbal y se tiene mayor elocuencia utilizando la imagen fotográfica como técnica de investigación.

Un punto vulnerable fueron los sanitarios ya que la mayoría carece de adecuaciones necesarias para utilizarse por personas con movilidad reducida en forma autónoma, independiente, sin requerir apoyo. Se encontraron mingitorios a alturas inalcanzables para quienes utilizan silla de ruedas o aquellos jóvenes que padecen mielomeningocele, solo por citar algunos casos. (Fig. 1).

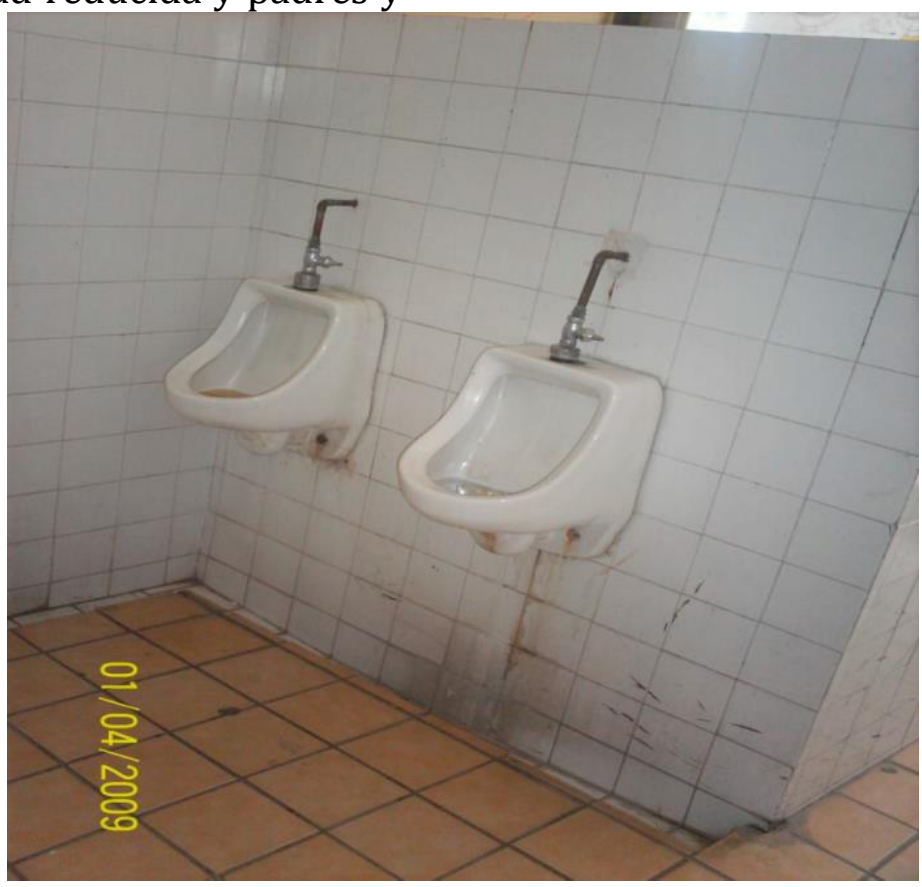

Figura 1. 
La "buena voluntad" no basta; para atender las necesidades de personas con discapacidad y ante la falta de empatía, se recurre a prácticas humillantes, que atentan a su dignidad, ante la falta de condiciones decorosas para realizar las más elementales necesidades fisiológicas, como el urinal que en una escuela le proporcionaron a un alumno que usa silla de ruedas, y que además lo mantenían colgado en la zona superior inalcanzable para éste, por lo que era necesaria la ayuda de alguien más al momento de acudir al sanitario. (Fig. 2).

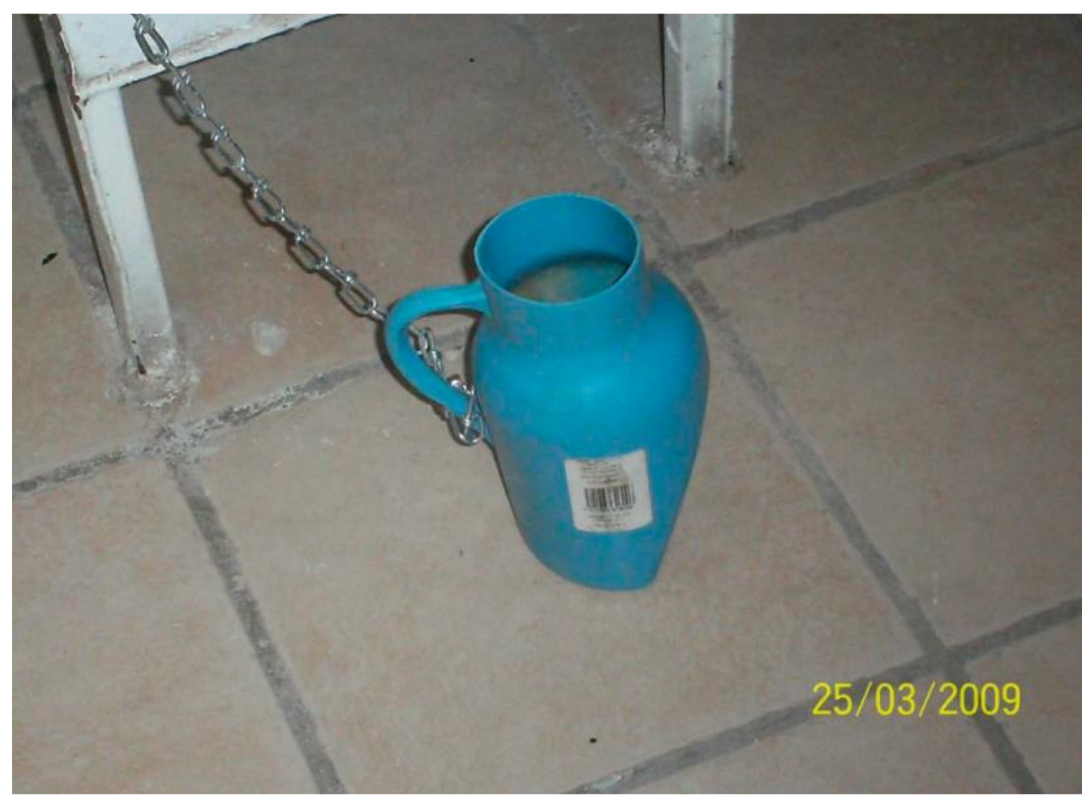

Figura 2.

El 91.3\% de las escuelas carecen de bebederos universalmente accesibles $y$, aunque en todos ellos se presentan muestras de "buena voluntad", no se ha alcanzado el objetivo de la accesibilidad. (Fig. 3). En algunas existe un tipo de bebederos que permite acceder desde una silla de ruedas, pero deben accionarse con el pie, lo que reduce su posibilidad de uso para quienes utilizan silla de ruedas por carecer de movilidad en sus extremidades inferiores. (Fig. 4). 


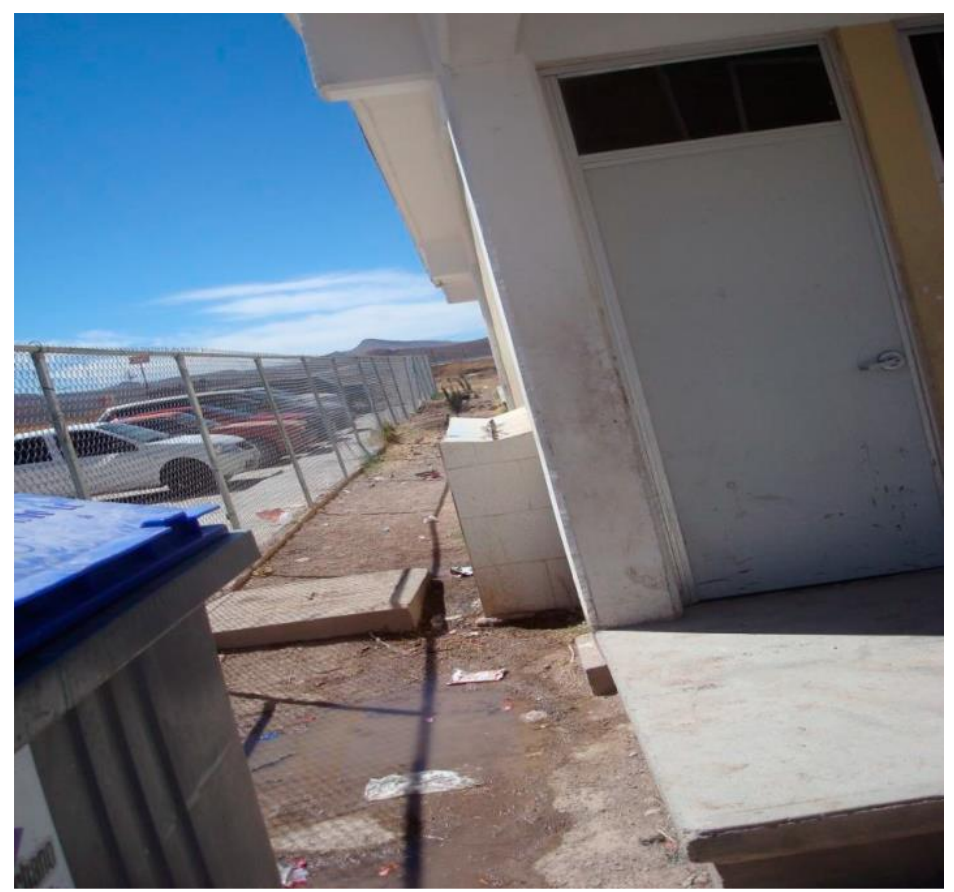

Figura 3.

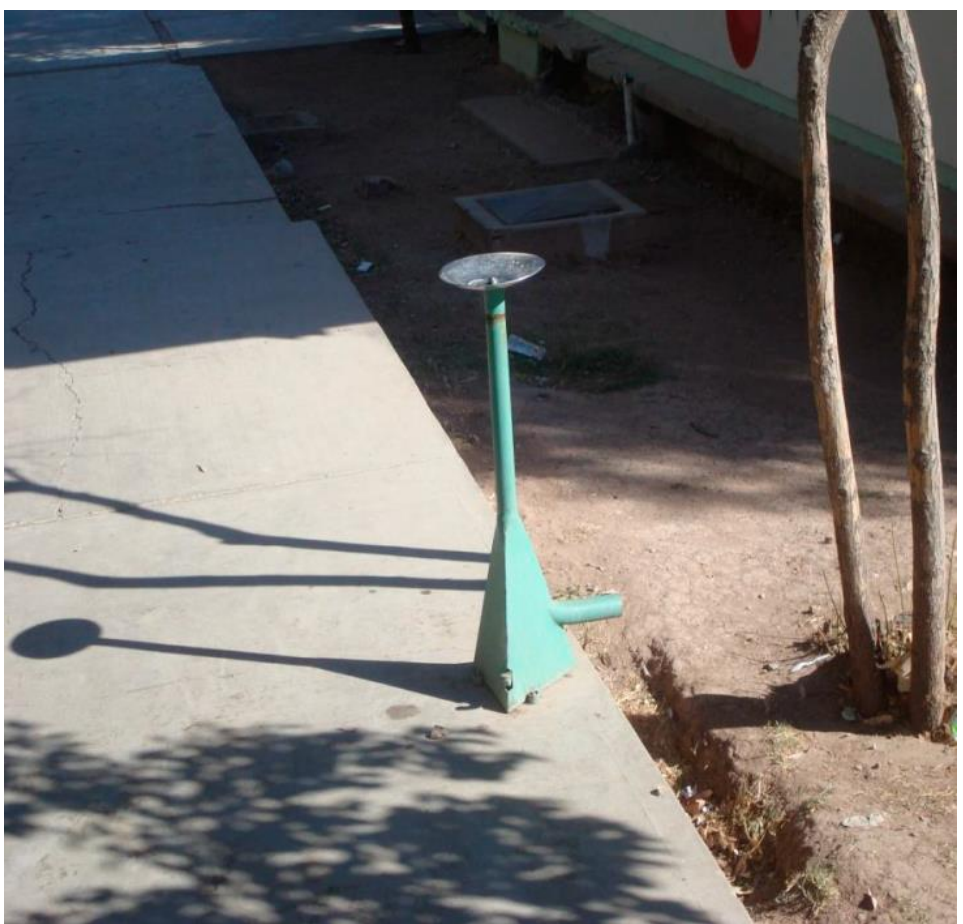

Figura 4.

Las rampas deben tener una inclinación de entre 6 y 9 grados (Fig. 5) para que se utilicen sin dificultad por cualquier persona, sin embargo, la enorme mayoría de las escuelas no cuentan con rampas adecuadas. (Fig. 6 y 7). 


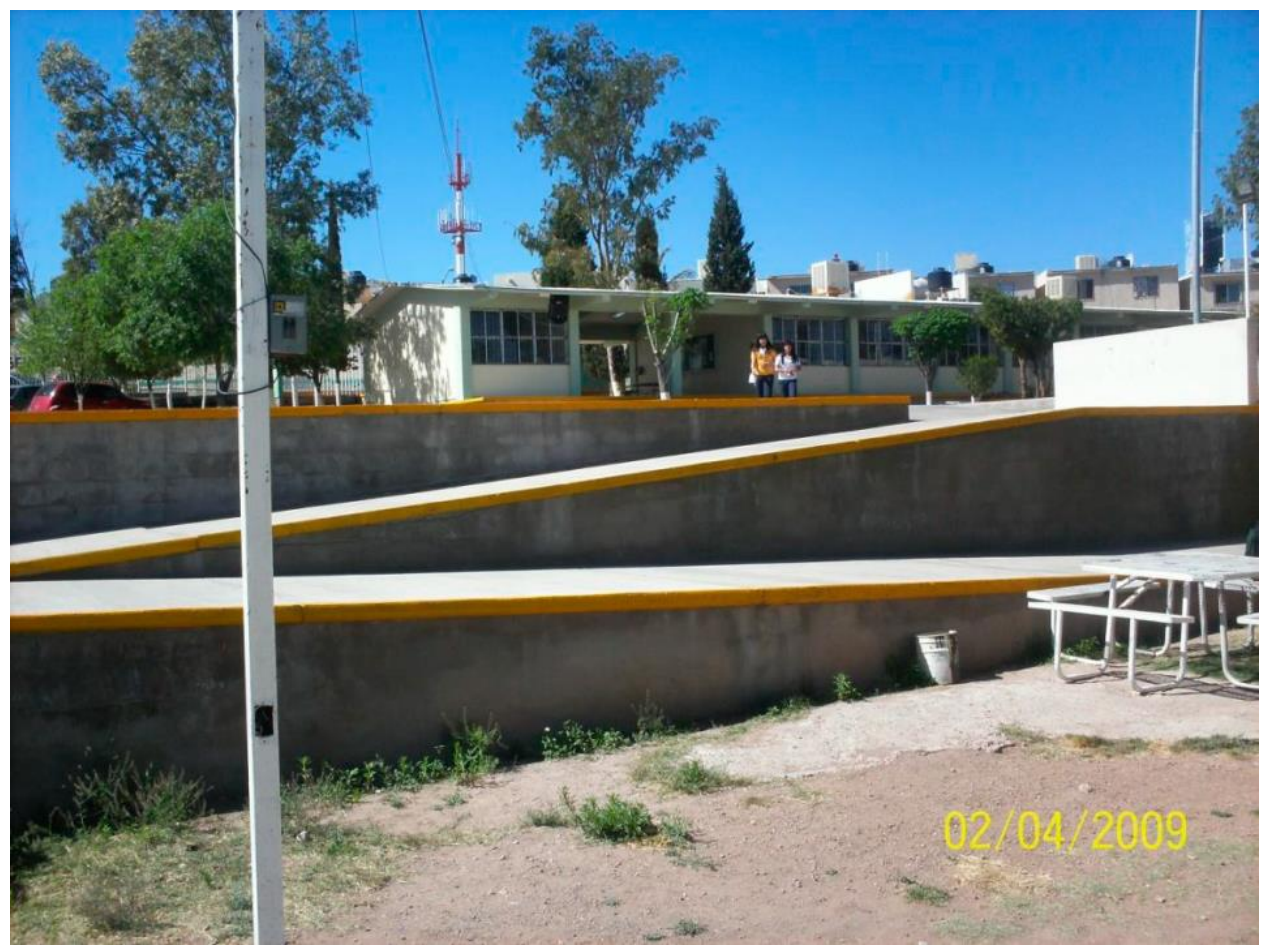

Figura 5.

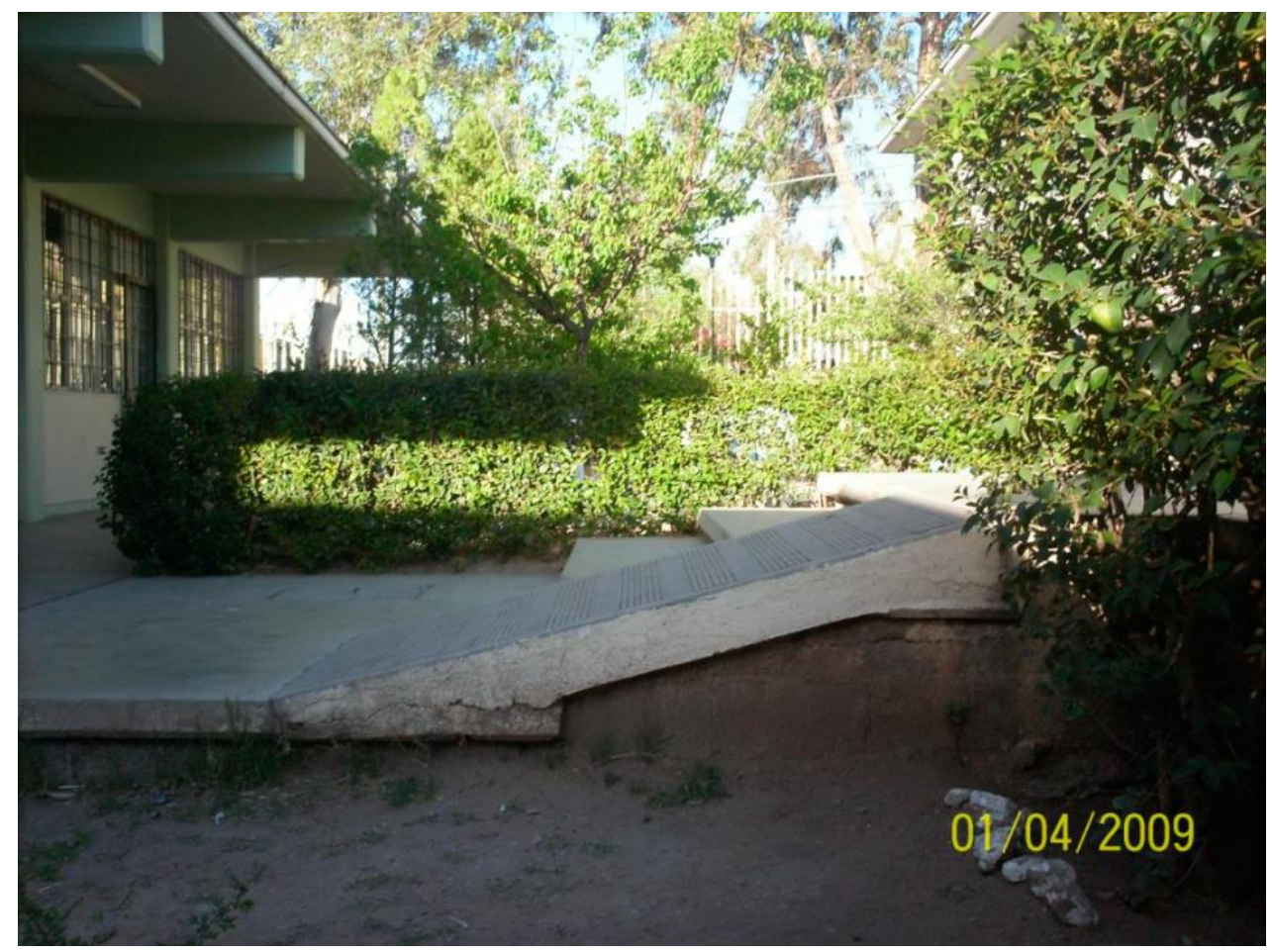

Figura 6. 


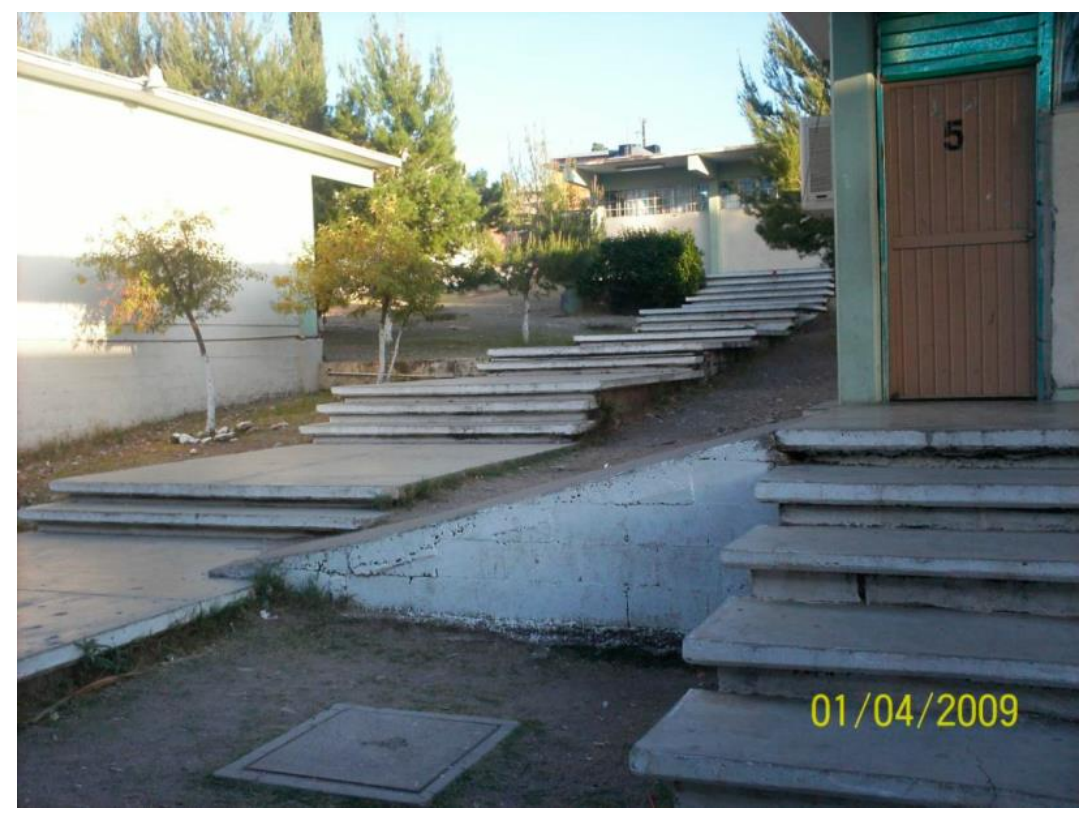

Figura 7.

Emergió un aspecto no considerado anticipadamente: puntos de riesgo de accidentes para el alumnado y personal que labora en las escuelas, al igual que para quienes acuden al edificio; estos accidentes pueden tener consecuencias fatales como la pérdida de la funcionalidad de cualquier miembro del cuerpo y el alto costo económico para el Estado que debe pagar una indemnización, todo por la negligencia en la construcción de los edificios escolares al no cuidar estos detalles (Fig. 8 y 9).

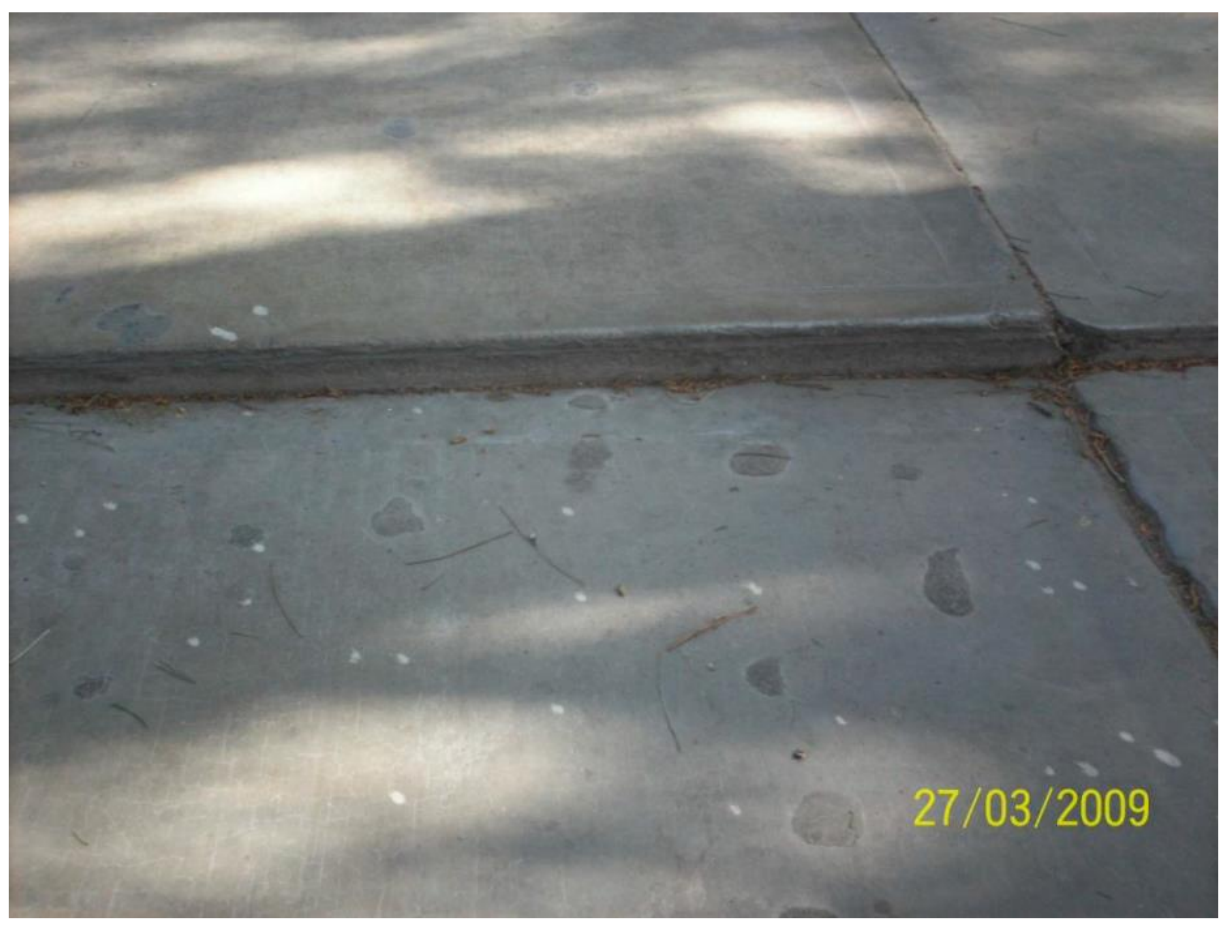

Figura 8. 


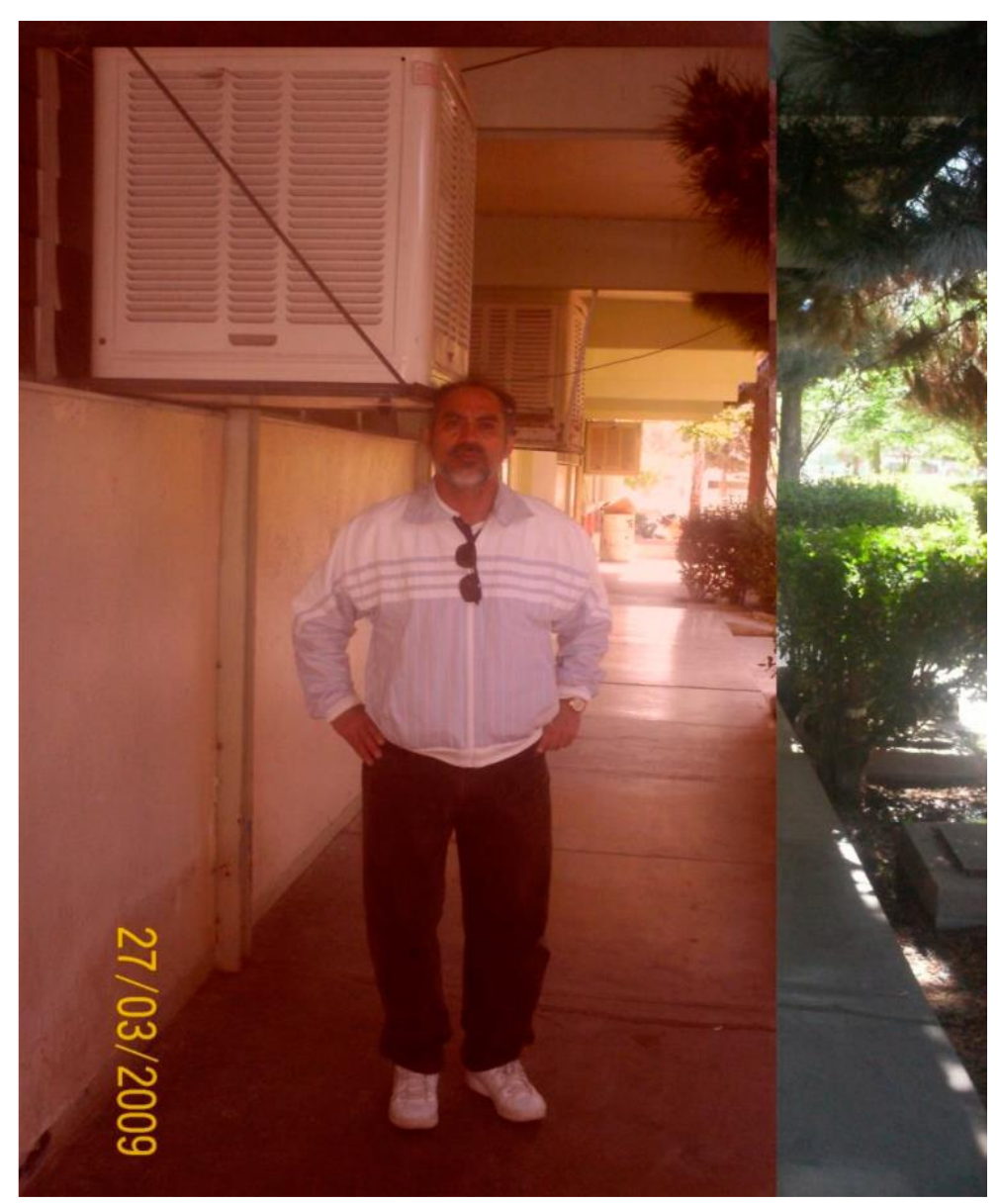

Figura 9.

Además de las cuestiones de infraestructura física, se encontraron barreras culturales, toda vez que las necesidades del alumnado y personal con dificultad motriz no son atendidas como debieran; una maestra debe subir a las aulas de la planta alta en las que trabaja, sentada de nalgas por las escaleras dada su imposibilidad para hacerlo de pie debido a un accidente laboral.

Un jovencito presenta movilidad disminuida en extremidades superiores por lo que no puede escribir y no hay un programa de atención por parte del profesorado que le imparte clases, debiendo ser sus compañeros y compañeras quienes le escriben las notas de clase en su cuaderno.

Una muestra más es el caso de una alumna que no tiene movilidad en sus piernas por lo que debe utilizar bastones $\mathrm{y}$, en su escuela, cuyos edificios son de dos plantas, se trabaja bajo la modalidad de aula-ciencia, sin considerar las dificultades y riesgos que esta alumna enfrenta cada hora que debe cambiarse de salón ya sea en planta alta o planta baja.

Dado lo anterior en cifras, datos y experiencias, me permito establecer las siguientes propuestas:

\section{Infraestructura física}

a) Que se legisle en relación a la construcción de los edificios escolares considerando la accesibilidad universal como premisa fundamental, privilegiando la inclusión y no solo la integración en nuestras escuelas. 
b) Que los terrenos destinados para la construcción de escuelas permitan que sean de un solo nivel.

c) Que se legisle, además, para que en los edificios escolares actuales, se realice una renovación profunda y eliminar las barreras arquitectónicas existentes e incluirles las características de accesibilidad universal.

d) Que el transporte escolar cuente con espacios especialmente diseñados para personas con discapacidad y tenga además implementos para el fácil acceso a ellos.

\section{Capacitación del personal}

a) Que se implemente un programa de acompañamiento académico para todas aquellas personas involucradas con la educación, principalmente a quienes laboran en las escuelas (docentes, directivos, de apoyo, administrativo, etc.) para que se les brinde la capacitación pertinente de forma adecuada y que al momento de recibir alumnado con discapacidad se enfrente el hecho como si se tratara de cualquier alumno "regular", buscando con ello la real inclusión educativa.

b) Que este acompañamiento sea de forma periódica y permanente $\mathrm{y}$ no solamente como un destello de buena voluntad temporal. Que forme parte de las políticas educativas, dado que la escuela constituye el espacio formativo que debiera ser el ejemplo social que provea un entorno en el que se ensayen nuevas formas de relación y las actitudes del profesorado y las que se promuevan entre el alumnado, tienen gran responsiva en ello.

El paradigma crítico de investigación permite describir y transformar el mundo en aras de lograr que sea más justo, libre y democrático. Contribuye a alterar la realidad y provocar el cambio, es aquí donde el presente trabajo centra su visión dado que se busca construir un entorno físico escolar incluyente que provea a sus actores, además de accesibilidad universal, una nueva visión que les permita adquirir la capacidad de influir y transformar el entorno exterior en pos de una sociedad incluyente y democrática, en tanto que en las escuelas no nace la discriminación pero sí es un lugar propicio para su reproducción; es el espacio en el que se gesta el modelo social, se descubren y se manifiestan situaciones conductuales por lo regular sumamente arraigadas que provocan que se vea como algo cotidiano y natural, se favorece la permanencia y aceptación, mostrándolo como un acto válido, (CONAPRED 2005), con lo que se confirma la insuficiente cobertura educativa para personas con discapacidad, que las cifras demuestran.

\section{Referencias}

CONAPRED (2005). La discriminación en la escuela. México: Dirección General Adjunta de Vinculación, Programas Educativos y Divulgación del Conapred.

Convención sobre los Derechos de las Personas con Discapacidad http://scm.oas.org/pdfs/2007/DIL00 140s.pdf; consultado el 21 de noviembre de 2008

Delors, Jacques y otros (1996). La educación encierra un tesoro. Informe a la UNESCO de la Comisión Internacional sobre la Educación para el siglo XXI. Revista Cubana de Educación Médica Superior. Consultado en (octubre, 16, 2008) en: http://bvs.sld.cu/revistas/ems/vol16_ 1_02/ems04102.pdf.

LEY FEDERAL PARA PREVENIR Y ELIMINAR LA DISCRIMINACIÓN Última Reforma DOF 27-11-2007

http://www.cddhcu.gob.mx/LeyesBib lio/pdf/262.pdf 
LEY GENERAL DE EDUCACIÓN Última Reforma DOF 15-07-2008 (http://www.cddhcu.gob.mx/LeyesBi blio/pdf/137.pdf)

LEY GENERAL DE LAS PERSONAS CON DISCAPACIDAD Última Reforma DOF 01-08-2008

(http://www.cddhcu.gob.mx/LeyesBi blio/pdf/LGPD.pdf)
Programa Nacional de Fortalecimiento de la Educación Especial y de la Integración Educativa. Todos en la misma escuela. Accesibilidad. Consultado en: http://normalista.ilce.edu.mx/normali sta/boletin/mismaesc/acces_a.pdf el día 23 de junio de 2008 